\title{
Immunocytokine augments local and abscopal response and animal survival when added to radiation and CTLA-4 checkpoint inhibition in a murine melanoma model
}

\author{
Zachary S Morris ${ }^{1 *}$, Emily I Guy ${ }^{1}$, David M Francis ${ }^{1}$, Monica M Gressett ${ }^{1}$, Eric A Armstrong ${ }^{1}$, Shyhmin Huang ${ }^{1}$, \\ Stephen D Gillies ${ }^{2}$, Alan J Korman ${ }^{3}$, Jacquelyn A Hank ${ }^{4}$, Alexander L Rakhmilevich', Paul M Harari ${ }^{1}$, Paul M Sondel ${ }^{5}$
}

From 30th Annual Meeting and Associated Programs of the Society for Immunotherapy of Cancer (SITC 2015) National Harbor, MD, USA. 4-8 November 2015

We have identified a cooperative interaction between radiation and intratumoral injection of anti-GD2 immunocytokine (hu14.18-IL2) in murine tumor models. In a moderate size $\left(\sim 200 \mathrm{~mm}^{3}\right)$, single tumor, B78 melanoma model this combination results in complete tumor regression in $71 \%$ of animals and a memory $\mathrm{T}$ cell response. We hypothesized that intratumoral immunocytokine would improve local and abscopal response to combined radiation and anti-CTLA-4 antibody.

Mice bearing large B78 tumors $\left(\sim 500 \mathrm{~mm}^{3}\right)$ were treated with single fraction (12Gy) or sham radiation, intratumoral

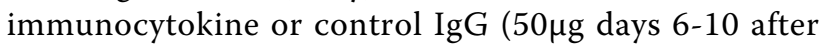
radiation), and intraperitoneal IgG2a anti-CTLA-4 or con-

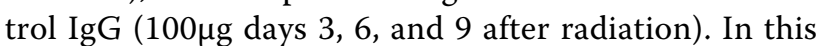
large tumor model the effect of combined radiation and immunocytokine was reduced ( $27 \%$ complete response) and addition of immunocytokine to radiation and antiCTLA-4 improved tumor response (73\% complete response) and animal survival compared to doublet combinations of these agents. In a model of microscopic metastatic disease generated by IV injection of animals bearing large primary B78 tumors $\left(\sim 500 \mathrm{~mm}^{3}\right)$ with $4 \times 10^{5}$ GD2deficient B16 melanoma cells (parental to B78) on the day of radiation, we observed improved survival with the addition of immunocytokine to combined radiation and antiCTLA-4.

However, in a model of established metastatic disease with a moderate size $\left(\sim 200 \mathrm{~mm}^{3}\right)$ primary B78 melanoma

'Dept. of Human Oncology, University of Wisconsin School of Medicine and Public Health, Madison, WI, USA

Full list of author information is available at the end of the article and a palpable $\left(\sim 50 \mathrm{~mm}^{3}\right)$ distant B78 tumor we did not observe an abscopal response when treating the primary tumor with radiation and intratumoral immunocytokine. Strikingly, when compared to animals with a single tumor we observed a profound inhibitory effect of the non-radiated second tumor such that primary tumor response to radiation and immunocytokine was indistinct from radiation alone in this two-tumor model. Delivering radiation to both the primary and secondary tumors eliminated this inhibitory effect of the secondary tumor. In this two-tumor model we combined primary tumor radiation and intratumoral immunocytokine with intraperitoneal IgG2b or IgG2a anti-CTLA-4. Both isotypes inhibit CTLA- 4 activity but the latter has a reportedly greater ability to deplete intratumoral regulatory $\mathrm{T}$ cells (Tregs). While IgG2b anti-CTLA-4 had minimal effect on primary tumor response to radiation and immunocytokine, IgG2a anti-CTLA- 4 rendered $80 \%$ of animals disease-free when given with radiation and immunocytokine, implicating Tregs in the suppressive effect of the second tumor on primary tumor response. In this two-tumor model, combination of radiation, immunocytokine, and IgG2a antiCTLA-4 enhanced primary tumor and abscopal response as well as survival compared to doublet combinations. Clinical trial designs to explore these findings will be presented.

\footnotetext{
Authors' details

'Dept. of Human Oncology, University of Wisconsin School of Medicine and Public Health, Madison, WI, USA. ²Provenance Biopharmaceuticals, Carlisle, MA, USA. ${ }^{3}$ Bristol-Myers Squibb Company, Redwood City, CA, USA. ${ }^{4}$ Department of Human Oncology, University of Wisconsin-Madison,
} 
Published: 4 November 2015

doi:10.1186/2051-1426-3-S2-P308

Cite this article as: Morris et al:: Immunocytokine augments local and abscopal response and animal survival when added to radiation and CTLA-4 checkpoint inhibition in a murine melanoma model. Journal for ImmunoTherapy of Cancer 2015 3(Suppl 2):P308.

Submit your next manuscript to BioMed Central and take full advantage of:

- Convenient online submission

- Thorough peer review

- No space constraints or color figure charges

- Immediate publication on acceptance

- Inclusion in PubMed, CAS, Scopus and Google Scholar

- Research which is freely available for redistribution

Submit your manuscript at www.biomedcentral.com/submit
() Biomed Central 